\title{
An Efficient and User-friendly Sinhala Input Method Based on Phonetic Transcription
}

\begin{abstract}
Sandeva Goonetilleke $^{\dagger}$, Yoshihiko Hayashi ${ }^{\dagger \dagger}$, Yuichi Itoh ${ }^{\dagger}$ and Fumio Kishino ${ }^{\dagger}$
We propose an application-independent Sinhala character input method called Sri Shell with a principled key assignment based on phonetic transcription of Sinhala characters. A good character input method should fulfill two criteria, efficiency and user-friendliness. We have introduced several quantification methods to quantify the efficiency and user-friendliness of Sinhala character input methods. Experimental results prove the efficiency and user-friendliness of our proposed method.
\end{abstract}

Key Words: Sinhala, Character Input Methods, Sri Shell

\section{Introduction}

The mother tongue of 14.6 million (74\% of the total Sri Lankan population of 19.7 million) Sri Lankans is Sinhala (State 2007). In Sri Lanka, there are three official languages, Sinhala, Tamil and English. Most of the governmental affairs in Sri Lanka are carried out in Sinhala. The education system also uses Sinhala up to the high school or university levels.

In Sri Lanka the use of computers has begun to spread rapidly due to the reduction in price and high performance. However, to date there is no well established method to input Sinhala scripts into the computer. Even though various kinds of Sinhala fonts and Sinhala input applications have been proposed, the language is still not well supported by computer systems. Hundreds of Sinhala fonts have been developed, but most of them have their own weaknesses. The character codes used in these fonts are the same as ASCII or sometimes Japanese character codes. As a result, in some cases Sinhala characters cannot be displayed together with foreign characters in the same context. Another problem is some rare Sinhala characters (such as $Q 9$, , in most of the fonts. Sinhala Unicode provides a good solution to this problem, but it is still not supported by most of applications and system software. On the other hand, there are very few available Sinhala input systems. On top of that, the major problems of the current input systems are the lack of user-friendliness and efficiency.

The objective of this research is to propose an efficient and user-friendly Sinhala input method based on phonetic notation, and to evaluate the efficiency and the user-friendliness compared with

\footnotetext{
$\dagger$ Graduate School of Information Science and Technology, Osaka University

t† Graduate School of Language and Culture, Osaka University
} 
other input methods. Here, efficiency is quantified by the average typing cost per Sinhala character, and user-friendliness is quantified by ease of remembering. We required 30 subjects to romanize the most frequently used 275 Sinhala characters. The average edit distance between romanized Sinhala characters and the input sequences of each input method is taken as a measurement of the difficulty of remembering. Our experimental results proved that the proposed input system Sri Shell gives the highest efficiency in most cases with a considerably high level of user-friendliness.

The rest of the paper is organized as follows. Chapter 2 provides a brief introduction of the Sinhala language. In Chapter 3 we discuss various Sinhala input methods proposed up to now, and their main features. The main features of the proposed input method Sri Shell are explained in Chapter 4. The evaluations are reported in Chapter 5. Chapter 6 concludes and outlines future work.

\section{Sinhala Language and Characters}

The modern "Sammata Sinhala Hōdiya" (Standard Sinhala Alphabet ${ }^{1}$ ) is made up of 60 basic characters (Unicode 2007), as shown in Table 1. These basic characters are modified to produce hundreds of conjunct characters that are also known as grapheme clusters (Unicode 2007), by adding various components (such as vowel signs, devowelizers and consonant signs). Because of this, the definition of a "character" may vary from person to person. As discussed later, to evaluate the "user-friendliness" and "efficiency" of an input method, it is vital to know the occurrence rate of each character. To this end, we need to define a "Sinhala character." Before giving the definition, we will discuss the main characteristics of the Sinhala language, the history of Sinhala Alphabet development, and how the conjunct characters are created. We use Mikami's notation (Mikami 2002) to explain the structure of Sinhala characters.

\subsection{Characteristics of Sinhala Language}

The Sinhala language is mainly spoken in Sri Lanka. It is also one of the official languages of Sri Lanka. It has 16 million speakers in total. This language is categorized under the "IndoEuropean: Indo-Iranian: Indo-Aryan: Southern zone: Sinhalese-Maldivian" language families (Gordon 2005). Sinhala language has its own writing system that is an offspring of the Brahmi script (Mikami 2002). The grammatical structures of spoken Sinhala differ from written Sinhala.

\footnotetext{
1 Alphabet: A character set that includes letters and is used to write a language.
} 
Table 1 Sammata Sinhala Hōdiya (Standard Sinhala Alphabet)

\begin{tabular}{|c|c|c|c|c|c|c|c|c|c|c|}
\hline \multirow{2}{*}{ Vowels } & $\begin{array}{l}\not{q} \\
\mathrm{a}\end{array}$ & $\begin{array}{l}\not \jmath \jmath \\
\bar{a}\end{array}$ & $\begin{array}{l}\check{c}_{2} \\
æ\end{array}$ & $\begin{array}{l}\mathscr{c}_{z} \\
\ddot{\circledast}\end{array}$ & $\begin{array}{l}9 \\
\mathrm{i}\end{array}$ & $\begin{array}{l}\% \\
\bar{i}\end{array}$ & $\begin{array}{l}c \\
u\end{array}$ & $\begin{array}{c}\mathrm{c}^{y} \\
\overline{\mathrm{u}}\end{array}$ & $\begin{array}{c}\text { «a } \\
r\end{array}$ & $\begin{array}{c}\text { ¿saa } \\
\overline{\mathrm{r}}\end{array}$ \\
\hline & $\begin{array}{c}09 \\
1\end{array}$ & $\begin{array}{c}\text { Q⿻尸一 } \\
\overline{1}\end{array}$ & $\begin{array}{l}\theta \\
e\end{array}$ & $\begin{array}{l}\theta^{\circ} \\
\overline{\mathrm{e}}\end{array}$ & $\begin{array}{c}\oplus 0 \\
\text { ai }\end{array}$ & $\begin{array}{l}\text { ( } \\
0\end{array}$ & $\begin{array}{l}\text { פิ } \\
\overline{0}\end{array}$ & $\begin{array}{l}\text { ఏొ } \\
\mathrm{au}\end{array}$ & & \\
\hline Diacritics & $\stackrel{\circ}{\mathrm{m}}$ & $\begin{array}{l}: \\
h \\
\end{array}$ & & & & & & & & \\
\hline \multirow{6}{*}{ Consonants } & $\begin{array}{l}28 \\
\mathrm{ka}\end{array}$ & $\begin{array}{c}\text { வ } \\
\text { kha }\end{array}$ & $\begin{array}{l}\text { ( ) } \\
\mathrm{ga}\end{array}$ & $\begin{array}{c}\text { es } \\
\text { gha }\end{array}$ & $\begin{array}{l}\text { ఏ } \\
\dot{n} \mathrm{a}\end{array}$ & $\begin{array}{c}\text { So } \\
\text { n̆ga }\end{array}$ & & & & \\
\hline & $\begin{array}{l}0 \\
\mathrm{ca}\end{array}$ & $\begin{array}{c}96 \\
\text { cha }\end{array}$ & $\begin{array}{l}36 \\
\mathrm{ja}\end{array}$ & $\begin{array}{l}300 \\
\text { jha }\end{array}$ & $\begin{array}{l}\text { ną } \\
\tilde{n} a\end{array}$ & $\begin{array}{c}\delta \\
\text { ňja }\end{array}$ & & & & \\
\hline & $\begin{array}{l}\partial \\
\text { ta }\end{array}$ & $\begin{array}{c}\text { c } \\
\text { tha }\end{array}$ & da & $\begin{array}{c}\text { eे } \\
\text { dha }\end{array}$ & $\begin{array}{l}\text { Dro } \\
\text { na }\end{array}$ & $\begin{array}{c}\text { ఏ } \\
\text { n̆ḍa }\end{array}$ & & & & \\
\hline & ta & $\begin{array}{c}\theta \\
\text { tha }\end{array}$ & $\begin{array}{c}\dot{c} \\
\text { da }\end{array}$ & $\begin{array}{c}\text { D } \\
\text { dha }\end{array}$ & $\begin{array}{l}3 \\
\text { na }\end{array}$ & $\begin{array}{c}\mathcal{C} \\
\text { n̆da }\end{array}$ & & & & \\
\hline & $\begin{array}{c}3 \\
\mathrm{pa}\end{array}$ & $\begin{array}{c}\text { g } \\
\text { pha }\end{array}$ & $\begin{array}{l}\text { อ } \\
\mathrm{ba}\end{array}$ & $\begin{array}{c}85 \\
\text { bha }\end{array}$ & $\begin{array}{l}\text { (9) } \\
\mathrm{ma}\end{array}$ & (9) & & & & \\
\hline & $\begin{array}{l}\omega \\
\mathrm{ya}\end{array}$ & $\begin{array}{c}\sigma \\
\mathrm{ra}\end{array}$ & $\begin{array}{l}\mathrm{C} \\
\text { la }\end{array}$ & $\begin{array}{l}\text { D } \\
\text { va }\end{array}$ & $\begin{array}{l}\text { so } \\
\text { śa }\end{array}$ & $\begin{array}{l}\text { a } \\
\text { sa }\end{array}$ & $\begin{array}{l}\mathrm{\omega} \\
\mathrm{sa}\end{array}$ & $\begin{array}{l}30 \\
\text { ha }\end{array}$ & $\begin{array}{l}e \\
\text { la }\end{array}$ & $\begin{array}{l}0 \\
\mathrm{fa}\end{array}$ \\
\hline
\end{tabular}

Written Sinhala has very complicated grammar compared to spoken Sinhala. For example the verb word form of written Sinhala depends on the tense, gender, and number, but in spoken Sinhala the verb word form depends only on the tense.

\subsection{Sinhala Họ̄iya (Sinhala alphabet)}

Hōdiya is a list of characters that defines all the basic characters of Sinhala. The "Śuddha Sinhala Hōdiya" ( pure Sinhala alphabet) has thirty-seven characters (twelve vowels and twenty-five consonants). Most of the Sinhala words can be written using only these thirty-seven characters. After the thirteenth century (Indrasēna 2001) the Sinhala language was very strongly influenced by Sanskrit and Pāli languages. As a result, many Sanskrit characters were incorporated into the Sinhala alphabet. The revised alphabet is called the "Miśra Sinhala Hōdiya" (Mixed Sinhala Alphabet). The "Miśra Sinhala Họ̄iya" consists of fifty-nine characters (eighteen vowels and forty-one consonants). The occurrence rate of these newly added twenty-two characters is lower than the original thirty-seven pure Sinhala characters. However, these new characters are frequently used in formal sentences. Thus they are also an indispensable part of the Sinhala alphabet. In the nineteenth and twentieth centuries, Sinhala language was strongly influenced by Portuguese, Dutch and English languages. Consequently the modern Sinhala alphabet also 
includes the 'f' sound. The modern "Sammata Sinhala Họdiya" ( standard Sinhala alphabet) consists of eighteen vowels and forty-two consonants (altogether sixty characters), as shown in Table 1.

\subsection{Sinhala Characters}

The Sinhala script belongs to the south indic scripts and is classified under the combining syllabics, which is a subset of the syllabary. Sinhala script is then further categorized as "a-Vowel Inherent Combining Syllabics" (Mikami 2002). A number of relevant concepts are described as follows.

Basic characters in Sinhala can be classified into three classes.

Vowel syllabics The first eighteen characters $(\subsetneq(a)$ to $ڤ y(a u))$ shown in Table 1 are vowel syllabics. The shapes of these characters never change. Thus these vowel syllabics are atomic characters (Unicode 2007). Mikami uses the symbol $V$ for this kind of character, and the pronunciation is represented by $v$.

Diacritics There are two diacritics in Sinhala, which are the anusvaraya $(\circ=m)$ and the visargaya $(:=h)$. These two characters can appear after any other vowel syllabic or a consonant syllabic. Mikami uses the symbol $\underline{D}$ for them.

Consonant syllabics The Sammata Sinhala Hōdiya has forty-two consonant syllabics as shown in the Table 1 Consonant section. All these consonant syllabics include the vowel sound $\subsetneq$ (= "a") which is called the inherent vowel. Mikami uses $C$ to represent these consonant syllabics and the pronunciation is denoted by $c v_{0}$, where $v_{0}=$ "a".

Sinhala grapheme clusters can have the following constructions. A grapheme cluster is in (Davis 2006) described as "what end users usually think of as characters."

Consonant-vowel combinations Vowel signs are used to change the inherent vowel ("a") of a consonant syllabics into another vowel. Mikami uses $\underline{V}$ to represent vowel signs, and the consonant-vowel combining characters are represented by $C \underline{V}$. These vowel signs are

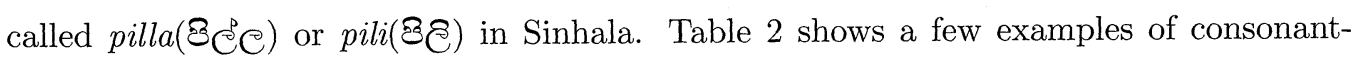
vowel combinations. Most of the vowel signs do not take different shapes corresponding to the consonant except the vowel sign for $\mathrm{u}$ ( $p \bar{a} p i l l a)$, which takes various shapes depending on the consonant.

Removing the inherent vowel In Sinhala pure consonants are also used in Sinhala scripts, not only at the end of a word but also in the middle of a word and at the beginning of a word. There are four ways to remove the inherent vowel $c(=a)$.

- Devowelizer A devowelizer is added to consonant syllabics in order to remove the 
Table 2 Examples of Consonant Vowel Combinations

\begin{tabular}{|c|c|c|c|c|c|c|c|c|c|c|c|c|c|c|c|c|}
\hline $\mathrm{v}$ & $\mathrm{a}$ & $\overline{\mathrm{a}}$ & $æ$ & $\overline{\not{x}}$ & $\mathrm{i}$ & $\overline{\mathrm{i}}$ & $\mathrm{u}$ & $\overline{\mathrm{u}}$ & $\underline{r}$ & $\underline{\mathrm{r}}$ & $\mathrm{e}$ & $\overline{\mathrm{e}}$ & ai & 0 & $\overline{\mathrm{o}}$ & $\mathrm{au}$ \\
\hline 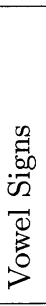 & 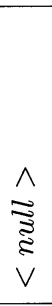 & 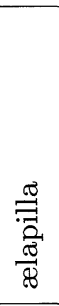 & 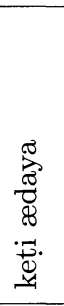 & 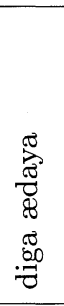 & 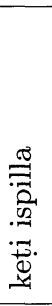 & 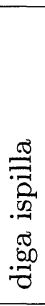 & 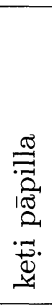 & 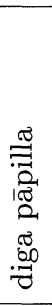 & 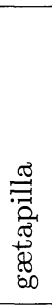 & 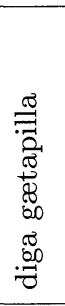 & 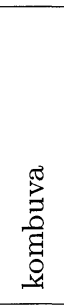 & 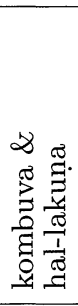 & 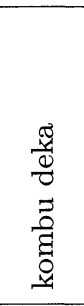 & 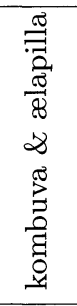 & 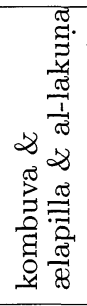 & 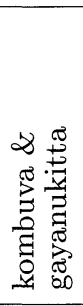 \\
\hline$\underline{\mathrm{V}}$ & & ) & 乙 & $\xi$ & $r$ & r & 0 & C & a & аа & 0 & $G^{\prime}$ & G० & (0) & 03 & 09 \\
\hline $\mathrm{t}$ & $\begin{array}{l}\partial \\
\text { ta }\end{array}$ & $\begin{array}{l}\text { Os } \\
\text { ța }\end{array}$ & $\begin{array}{l}\partial_{2} \\
\text { tææ }\end{array}$ & $\begin{array}{l}\partial_{z} \\
t \bar{æ}\end{array}$ & $\begin{array}{l}\delta \\
\text { ți }\end{array}$ & $\begin{array}{l}8 \\
\text { ți }\end{array}$ & $\begin{array}{l}\text { a } \\
\text { tu }\end{array}$ & $\begin{array}{l}\text { व } \\
\text { țu }\end{array}$ & $\begin{array}{l}\text { Oa } \\
\text { tr }\end{array}$ & $\begin{array}{l}\text { Oaa } \\
\text { ț̣ }\end{array}$ & $\begin{array}{l}\odot \circlearrowright \\
\text { te }\end{array}$ & $\begin{array}{l}\odot \circlearrowright \\
\text { țe }\end{array}$ & $\begin{array}{c}\odot \odot \diamond \\
\text { tai }\end{array}$ & $\begin{array}{l}\text { बठ } \\
\text { to }\end{array}$ & $\begin{array}{c}\odot \partial f^{\circ} \\
\text { țō }\end{array}$ & 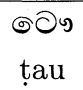 \\
\hline $\mathrm{p}$ & $\begin{array}{l}3 \\
\mathrm{pa}\end{array}$ & $\begin{array}{l}\text { 3ง } \\
\text { pā }\end{array}$ & $\begin{array}{l}32 \\
\text { pæ }\end{array}$ & 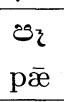 & $\begin{array}{l}83 \\
\mathrm{pi}\end{array}$ & $\begin{array}{l}\overline{8} \\
\mathrm{p} \overline{\mathrm{i}}\end{array}$ & $\begin{array}{c}99 \\
\mathrm{pu}\end{array}$ & $\begin{array}{l}\hat{g} \\
\mathrm{pu}\end{array}$ & $\begin{array}{l}\text { Oa } \\
\text { pr }\end{array}$ & $\begin{array}{l}\text { ওaa } \\
\text { p } \vec{r}\end{array}$ & $\begin{array}{l}\odot 3 \\
\text { pe }\end{array}$ & $\begin{array}{l}\text { ब๐ } \\
\text { pē }\end{array}$ & $\begin{array}{c}\odot \odot ৩ ~ \\
\text { pai }\end{array}$ & $\begin{array}{c}\odot 3 \jmath \\
\text { po }\end{array}$ & $\begin{array}{l}\odot 3 \delta^{\circ} \\
\text { pō }\end{array}$ & $\begin{array}{l}\odot ও \vartheta \\
\text { pau }\end{array}$ \\
\hline $\mathrm{k}$ & $\begin{array}{l}\text { D) } \\
\text { ka }\end{array}$ & נō & $\begin{array}{l}\Phi_{2} \\
k æ 2\end{array}$ & $\begin{array}{l}\mathscr{D}_{z} \\
k \bar{æ}\end{array}$ & $\begin{array}{l}\text { బิ) } \\
\mathrm{ki}\end{array}$ & $\begin{array}{l}\text { 26) } \\
\mathrm{k} \overline{\mathrm{i}}\end{array}$ & $\begin{array}{l}\text { వ } \\
\mathrm{ku}\end{array}$ & $\begin{array}{l}\text { ฉூ } \\
k \bar{u}\end{array}$ & $\begin{array}{l}\text { roa } \\
\mathrm{kr}\end{array}$ & $\begin{array}{l}\text { żaa } \\
\mathrm{k} \bar{r}\end{array}$ & $\begin{array}{c}\text { のర) } \\
\text { ke }\end{array}$ & $\begin{array}{l}\odot \varpi)^{\circ} \\
\mathrm{ke}\end{array}$ & $\begin{array}{c}\text { ๑๐ } \\
\text { kai }\end{array}$ & $\begin{array}{c}\text { のவை } \\
\text { ko }\end{array}$ & $\begin{array}{c}\odot 20 j^{\circ} \\
k \bar{o}\end{array}$ & $\begin{array}{l}\text { のனை } \\
\mathrm{kau}\end{array}$ \\
\hline$!$ & $\begin{array}{l}E \\
\text { la }\end{array}$ & $\begin{array}{l}e^{o} \\
\text { laa }\end{array}$ & $\begin{array}{l}e z \\
l æ\end{array}$ & $\begin{array}{l}\mathcal{E} \\
l \dddot{\circledast}\end{array}$ & $\begin{array}{l}E \\
\text { li } \\
\end{array}$ & $\begin{array}{l}\text { êd } \\
\overline{\mathrm{i}}\end{array}$ & $\begin{array}{l}\theta \\
\text { lu }\end{array}$ & $\begin{array}{l}\vartheta_{z} \\
l \bar{u}\end{array}$ & & & $\begin{array}{c}\text { ๑e } \\
\text { le }\end{array}$ & $\begin{array}{c}\text { ๑e } \\
\text { lēe }\end{array}$ & $\begin{array}{c}\text { बఠe } \\
\text { lai }\end{array}$ & $\begin{array}{c}\odot e^{\circ} \\
\text { lo }\end{array}$ & $\begin{array}{c}\odot e^{p} \\
l ̣ \bar{o}\end{array}$ & $\begin{array}{l}\text { बe } \\
\text { lau }\end{array}$ \\
\hline
\end{tabular}

inherent vowel sound. This is the most general way to remove the inherent vowel, but it has a lower priority compared to other specific inherent vowel removers. In Sinhala this devowelizer is called the hal-lakuna. There are two shapes for hallakuna and one of them is selected depending on the shape of the consonant syllabic. Mikami uses $X$ to represent this devowelizer. A few examples are shown in Table 3. In Shape 1 a flag-like symbol is added at the end of the character, and in Shape 2 the top ending line is doubled by reversing it.

- Consonant signs In some cases consonant signs are used to devowelize the inherent vowel. There are three consonant signs: yamsaya, rakarāmśaya and rēphaya. If the consonant next to the devowelized consonant is $\omega(=$ ya) then $v$ (yamsaya) is used. If the consonant next to the devowelized consonant is $\sigma(=\mathrm{ra})$, then rakarāmśaya is

Table 3 Examples of Devowelizers (two shapes)

\begin{tabular}{|c|c|c|c|c|c|c|c|c|c|c|}
\hline & \multicolumn{5}{|c|}{ Shape 1} & \multicolumn{5}{|c|}{ Shape 2} \\
\hline $\mathrm{C}$ & $\begin{array}{l}\text { (1) } \\
\text { ka }\end{array}$ & $\begin{array}{l}\text { o } \\
\text { ga }\end{array}$ & $\begin{array}{l}6 \\
\text { ja }\end{array}$ & $\begin{array}{l}n \\
\text { na }\end{array}$ & $\begin{array}{l}\omega \\
\text { ya }\end{array}$ & $\begin{array}{l}\text { (D) } \\
\text { ca }\end{array}$ & $\begin{array}{l}\partial \\
\text { ta }\end{array}$ & $\begin{array}{l}\text { D } \\
\text { da }\end{array}$ & $\begin{array}{l}\text { D } \\
\text { va }\end{array}$ & $\begin{array}{c}\text { (9) } \\
\mathrm{ma}\end{array}$ \\
\hline CX & $\begin{array}{l}\text { "8) } \\
k\end{array}$ & $\begin{array}{l}5^{p} \\
g\end{array}$ & $\begin{array}{l}0 \\
j\end{array}$ & $\begin{array}{c}3^{\circ} \\
n\end{array}$ & cs & อิ & $\begin{array}{l}\partial \\
t\end{array}$ & $\begin{array}{l}\text { ఏి } \\
\mathrm{d}\end{array}$ & $\begin{array}{l}\text { Dิ } \\
\mathrm{V}\end{array}$ & (9) \\
\hline
\end{tabular}


Table 4 Examples of Consonant Signs

\begin{tabular}{|c|c|c|c|c|c|c|c|c|c|c|}
\hline & \multicolumn{5}{|c|}{ Yamsaya } & \multicolumn{5}{|c|}{ Rakarāṃśaya } \\
\hline Incorrect & అิఱ & Sics & Dins & Bं & Sics & 30 & sిర & "విర & 86 & sib \\
\hline Correct & (9) & as & 2015 & a) & as & $\ddot{9}$ & 29 & 20) & 26 & (3) \\
\hline & mya & tya & kya & șa & nya & pra & tra & $\mathrm{kra}$ & jra & śra \\
\hline
\end{tabular}

Table 5 Examples of Half Letters

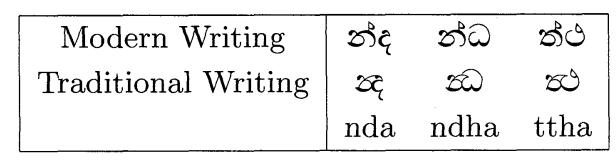

used. These two consonant signs have a higher priority compared to the devowelizer. A few examples are shown in Table 4.

The third consonant sign is called rēphaya and it is exactly equivalent to $\measuredangle(=r)$. As this rēphaya is extremely rare in modern Sinhala text, we do not take this into account in our evaluations. This consonant sign is optional in modern Sinhala. Mikami uses $\underline{C}$ to represent consonant signs.

- Half-letters Half letters can be used instead of devowelizers. However this is also optional. Nowadays these half letters are also very rare, thus we exclude them in our evaluations. A few examples are shown in Table 5.

- Special characters (or Conjunct consonants) Traditionally there were many special characters in use, but currently only one special character remains. This

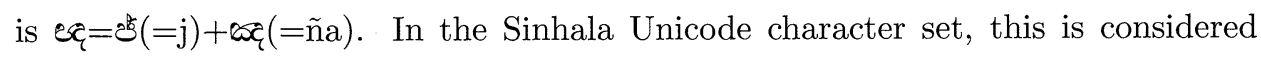
an independent character. In our evaluation we also consider it an independent Sinhala character.

\subsection{Definition of Character}

We now give a definition of a Sinhala character. Let $T$ be an arbitrary Sinhala text and $f_{0} \ldots f_{n}$ be the phonetic notation of $T$. This phonetic notation can be NLAC (National Library at Calcutta romanization) or IPA (International Phonetic Alphabet) or an input string of any phonetic based 
Table 6 Conjunct consonants derived from $\approx(=\mathrm{ka})$

\begin{tabular}{|c|c|c|c|c|c|c|c|c|c|c|c|c|c|}
\hline 20 & נדם & 28 & $28\}$ & ฉิ & ฉి & "ి & "ి & ๑ా & ๑జా & எのరి & ๑வை & ๑జు & ๑20 \\
\hline $\mathrm{ka}$ & $\mathrm{k} \overline{\mathrm{a}}$ & $\mathrm{k} æ$ & $\mathrm{k} \bar{\circledast}$ & $\mathrm{ki}$ & $\mathrm{k} \overline{\mathrm{i}}$ & $\mathrm{ku}$ & $\mathrm{k} \overline{\mathrm{u}}$ & ke & $k \overline{\mathrm{e}}$ & kai & ko & kō & kau \\
\hline 2 & వ్రా & 29ర్ర & వ్రి & బ్రి & వ్రి & 2 & 20 & ๑20 & ๑2వ్రీ & ৫๑ற్ర & ๑వ్రు & (వ⿹勹రJ & ('వ్రం \\
\hline $\mathrm{kra}$ & krā & kræ & krǣ & kri & $\mathrm{kr} \overline{\mathrm{i}}$ & $\mathrm{kru}$ & krū & kre & $\mathrm{kr} \overline{\mathrm{e}}$ & krai & kro & krō & krau \\
\hline 2015 & 20150 & & & & & 2) & 2015 & axs & - విక & & అவைง & (1) & \\
\hline kya & kyā & & & & & kyu & kyū & kye & kyē & & kyo & kyō & \\
\hline ద & ฉి & Daa & & & & & & & & & & & \\
\hline $\mathrm{k}$ & $\mathrm{kr}$ & $k \bar{r}$ & & & & & & & & & & & \\
\hline
\end{tabular}

Sinhala input system. Then we can define a function such that, $T=$ phonetic_to_Sinhala $\left(f_{0} \ldots f_{n}\right)$.

$$
\begin{aligned}
\exists i, j, \text { and }, i \leq j & \\
T= & \text { phonetic_to_Sinhala }\left(f_{0} \ldots f_{i-1}\right) \\
& + \text { phonetic_to_Sinhala }\left(f_{i} \ldots f_{j}\right) \\
& + \text { phonetic_to_Sinhala }\left(f_{j+1} \ldots f_{n}\right)
\end{aligned}
$$

and, $\forall k, i \leq k<j$

$$
T \neq \text { phonetic_to_Sinhala }\left(f_{0} \ldots f_{k}\right)+\text { phonetic_to_Sinhala }\left(f_{k+1} \ldots f_{n}\right)
$$

where, + means to simply concatenate the two strings.

Then, phonetic_to_Sinhala $\left(f_{i} \ldots f_{j}\right)$ is defined as a single Sinhala character.

According to Mikami's notation a Sinhala character can be represented by the following combinations.

$$
S:=V|C| C \underline{V}|C X| C \underline{C}|C \underline{C V}| \underline{D}
$$

Table 6 shows all the characters derived from Sinhala character $\sim(=\mathrm{ka})$. All other consonants also produce derivatives similarly. As a result Sinhala language has hundreds of characters.

\section{Sinhala Input Systems}

This section reviews the representative Sinhala input systems proposed so far.

\subsection{Direct Input Method}

Sinhala fonts assign Sinhala characters to the ASCII character code. For example, Sinhala $c$ (=a) was assigned to 0x61 (=ASCII ' $\mathrm{a}$ ') . In the direct input method, users have to input 
the character codes as assigned in a specific Sinhala font as shown in Figure 1. Some of the Sinhala fonts use character codes between $0 \times 80 \sim 0 \mathrm{xFF}$. As there are no keys assigned for these character codes in the normal English keyboard, users have to refer to a character code table to input Sinhala text.

Later some improved versions of Sinhala fonts have been introduced. These fonts assign character codes to the vowels, consonants and vowel signs. With this method, the binary range used is reduced to $0 \mathrm{x} 20 \sim 0 \mathrm{x} 7 \mathrm{~F}$. Thanks to these fonts, it became possible to type Sinhala text using a normal English keyboard. Although some rare Sinhala characters are missing, these fonts are used very widely. A typical example of this kind of font is the "kaputadotcom" font ${ }^{2}$. Most of the online Sinhala sites including news sites use these kinds of fonts.

\section{$3.2 \quad$ Natural SinGlish}

Even though it is possible to type Sinhala text using the direct input method, there is just a key for each Sinhala character (or a part of a character). For this reason, this key assignment is far from intuitive. To resolve this problem the Natural SinGlish (Sasanka 2004) typing method was introduced by A.D.R. Sasanka. This system converts the input sequence that is more natural for users into character codes as shown in Figure 1. English spellings and the English pronunciations

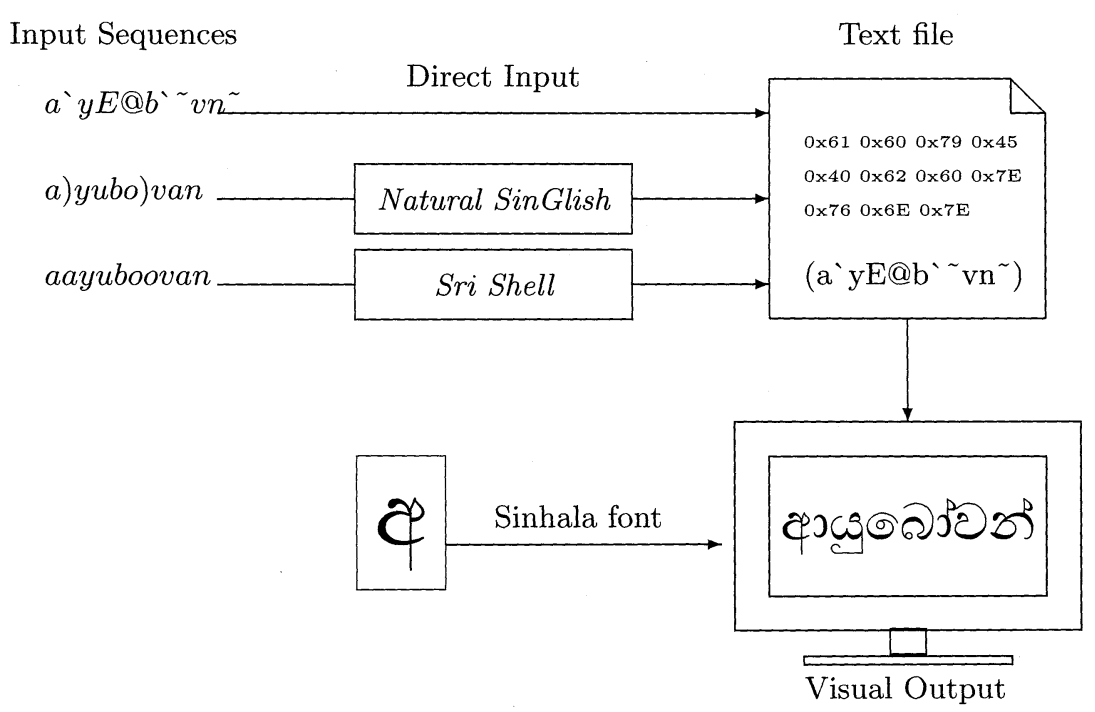

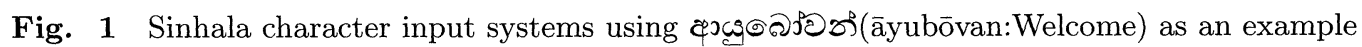

\footnotetext{
2 http://www.info.lk/slword/news.htm
} 


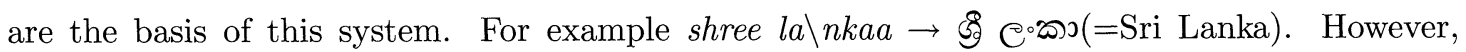
Sinhala language has many more characters than English. To avoid ambiguity, this system has introduced several techniques, such as:

- Capitals

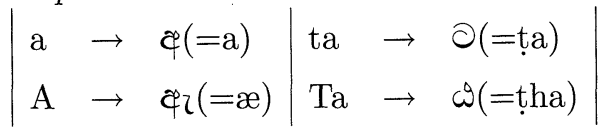

- Key combinations

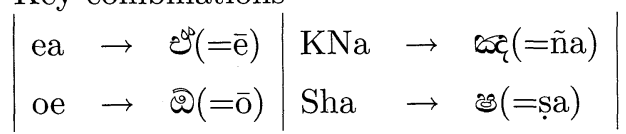

- Dead keys: “\" is used as a dead key

$$
\begin{aligned}
& \backslash \mathrm{n} \rightarrow \circ(=\mathrm{y}) \\
& \backslash \mathrm{h} \rightarrow \circ(=\mathrm{h})
\end{aligned}
$$

This system is simply based on English spellings, making the system quite complex. The sounds that have phonetic similarities cannot be typed in a similar manner.

$$
\begin{aligned}
& \mathrm{ka} \rightarrow \boldsymbol{\sim}(=\mathrm{ka}) \text { and } \mathrm{kha} \rightarrow \gtrsim(=\mathrm{kha}) \\
& \text { ta } \rightarrow \partial(=\text { ța }) \text { but tha } \nrightarrow \omega(=\text { ṭha }) \\
& \text { da } \rightarrow \bigotimes(=d a) \text { and nnda } \rightarrow \text { } \rightarrow(=\text { ñda })
\end{aligned}
$$

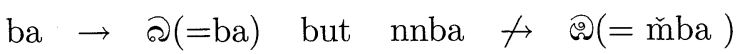

This system is not very efficient in some cases, because it uses a lot of upper case letters in the middle of the words, where the user needs to press and release the shift-key repeatedly.

\section{Proposed system}

Here we propose a Sinhala typing system called Sri Shell. Sri Shell assigns a key combination to each Sinhala character. The basis of this system is the phonetic notation of Sinhala characters. Table 7 shows the Sinhala characters, phonetic notation using NLAC (National Library at Calcutta romanization), phonetic notation using IPA (International Phonetic Alphabet), and the key assignment by Sri Shell.

Unlike the Natural SinGlish, Sri Shell has been implemented as an independent module, which allows the input of Sinhala text into any application program.

\section{Principles of the proposed system}

- It is based on phonetic notation of the characters:

- All aspirated consonants can be produced by adding an " $\mathrm{h}$ " to the unaspirated consonants. 
Table 7 Sinhala characters, phonetic notations (NLAC [IPA]) and Sri Shell

Vowels and vowel diacritics

\begin{tabular}{|c|c|c|c|c|c|c|c|c|c|c|}
\hline \multirow{3}{*}{$\begin{array}{c}\text { Sin.Ch. } \\
\text { NLAC[IPA] } \\
\text { Sri Shell }\end{array}$} & $\begin{array}{c}\dot{c} \\
\mathrm{a}[\mathrm{a}, \partial] \\
a\end{array}$ & $\begin{array}{c}\mathrm{C}^{\mathrm{J}} \\
\overline{\mathrm{a}}[\mathrm{a} \mathrm{a}, \mathrm{a}] \\
a a\end{array}$ & $\begin{array}{c}\not \varkappa \\
æ[æ] \\
a e\end{array}$ & $\begin{array}{c}\mathscr{q} z \\
\bar{x}[\text { ae: }] \\
\text { aee }\end{array}$ & $\begin{array}{c}9 \\
\mathrm{i}[\mathrm{i}] \\
i\end{array}$ & $\begin{array}{c}\% \\
\overline{\mathrm{i}}[\mathrm{ir}] \\
i i\end{array}$ & $\begin{array}{c}\mathrm{C} \\
\mathrm{u}[\mathrm{u}] \\
u\end{array}$ & $\begin{array}{c}\mathrm{C}^{\mathrm{y}} \\
\overline{\mathrm{u}}[\mathrm{us}] \\
u u\end{array}$ & $\begin{array}{c}\text { «a } \\
\mathrm{r}[\mathrm{r}] \\
r x\end{array}$ & $\begin{array}{c}\text { «saa } \\
\overline{\mathrm{r}}[\mathrm{rg}:] \\
r x x\end{array}$ \\
\hline & $\theta \theta$ & \&ay & $\theta$ & $\theta^{\infty}$ & बఅ & ๑ & ๑ิ & Q9 & $(\Varangle) \circ$ & $(\xi):$ \\
\hline & $\begin{array}{l}1[1]] \\
l x x\end{array}$ & $\begin{array}{l}\overline{1}[! !:] \\
l x x x\end{array}$ & $\begin{array}{c}\mathrm{e}[\mathrm{e}] \\
e\end{array}$ & $\begin{array}{c}\overline{\mathrm{e}}[\mathrm{e}: \mathrm{e}] \\
e e\end{array}$ & $\begin{array}{c}\text { ai [ai] } \\
a i\end{array}$ & $\begin{array}{c}\mathrm{o}[\mathrm{o}] \\
o\end{array}$ & $\begin{array}{c}\bar{o}[\mathrm{o:}] \\
o o\end{array}$ & $\begin{array}{c}\mathrm{au}[\mathrm{au}] \\
\mathrm{au}\end{array}$ & $\begin{array}{c}m \text { m [y] } \\
/ n\end{array}$ & $\begin{array}{c}\text { he [h] } \\
h x\end{array}$ \\
\hline
\end{tabular}

\section{Consonants}

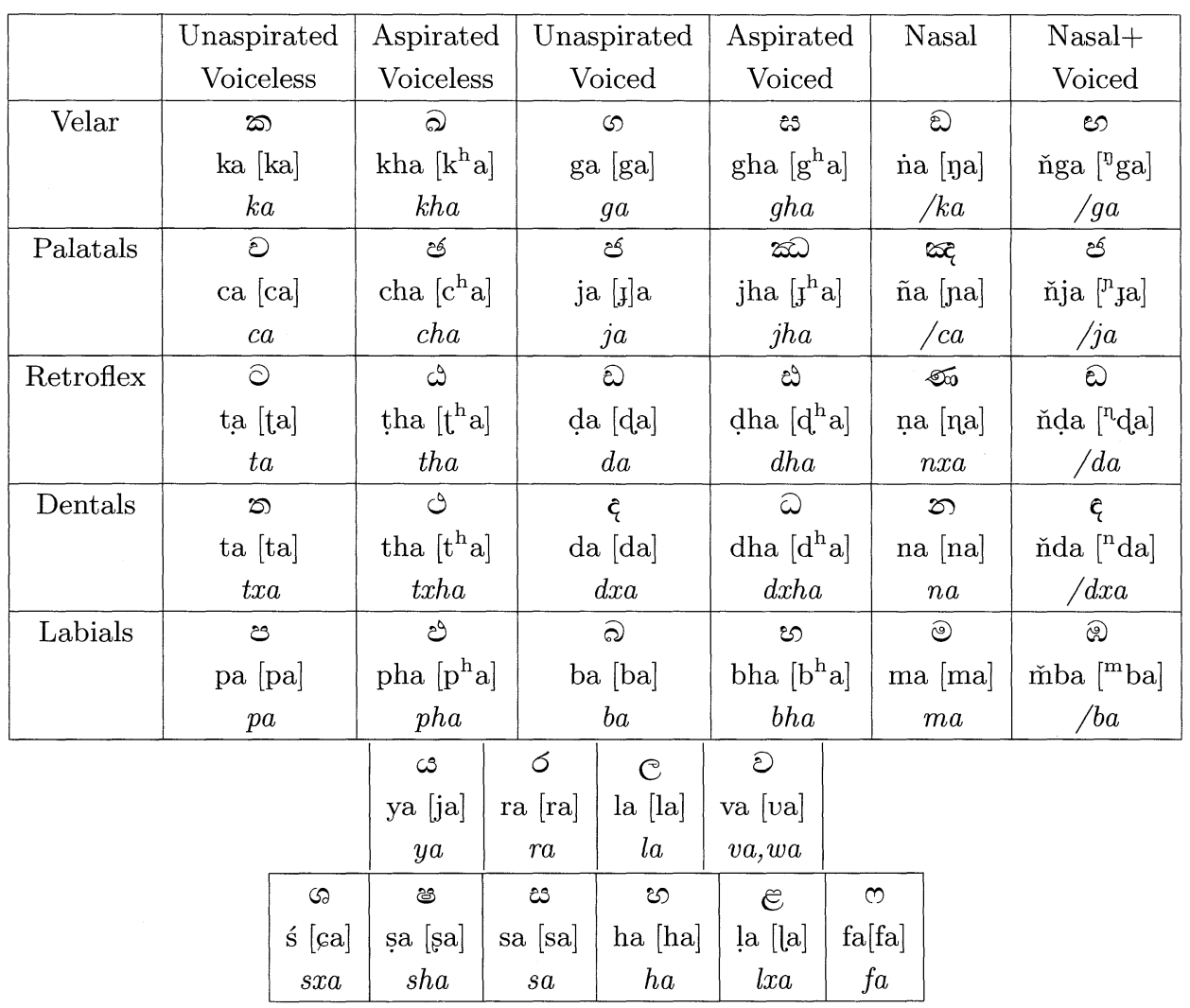

- Nasals can be produced by voiceless vowel preceded by "/".

- Nasal+voiced can be produced by voiced vowel preceded by "/".

- It is consistent:

- All long-vowels can be produced by doubling the last character of a short-vowel.

- If two Sinhala characters map to the same roman character, then these Sinhala characters are differentiated by adding an "x." The " $x$ " is added to the one that 
has a lower occurrence rate.

(for example retroflex \& dental, Table 7)

- It is complete:

Most of the Sinhala input systems introduced up to now have several missing characters. Especially rare characters such as «a , waa , proposed system supports all the characters even though some of them cannot be displayed with most of the fonts.

\section{Evaluation}

This section describes the evaluation of the proposed input method. The evaluation of an input method should be based on user friendliness, as well as input efficiency. We can evaluate the input efficiency by simply measuring the time taken to input a prepared text. For example, Masui measured the average input time that was necessary to input a prepared text with 53 characters (Masui 1998). This principle applies not only to the evaluation of an input method for a language with a small number of characters, but also for a language with many characters.

The user-friendliness evaluation of an input method, on the other hand, should be greatly different between two language types. Each character that appears in conventional English texts can be assigned a unique key on a typical English keyboard. The correspondence between a character and a key is 1-to-1, enabling the user to input texts without performing any conversions.

In this setting, the physical arrangement of the keys and the mapping of keys to a set of characters are crucial. Dominic et al. (Dominic Hughes and Warren 2002) proposed a method for predicting maximum typing speeds with such key arrangements. The purpose of their proposal was to provide a tool that makes the development process of a user interface more efficient; the usual development process involves an initial evaluation backed up by mathematical models, as well as a final evaluation through fully empirical testing.

However, in an input method for a language with many characters, we need some conversion process that maps the input key sequence into a linguistic expression in some representation form in the target language. A typical example of such a method is kana-kanji conversion-based Japanese input methods, with which we get Kanji characters usually by inputting the associated romanized character sequence; each of the characters can be directly mapped into alpha keys with ordinary English keyboards. There is no difficulty in inputting alpha key sequences because there are only a few standard conversion rules for romanizing Japanese expressions. Also, the rules are well known even to average users. 
Table 8 Occurrence rates of Sinhala characters

\begin{tabular}{lcccc}
$\#$ & character & & occurrence rate & accumulated frequency \\
\hline 1 & $\omega$ & (=ya) & $4.4434 \%$ & $4.4434 \%$ \\
2 & 0 & $(=\mathrm{va})$ & $4.1540 \%$ & $8.5975 \%$ \\
$\vdots$ & $\vdots$ & & $\vdots$ & $\vdots$ \\
274 & கे & $(=\mathrm{f})$ & $0.0161 \%$ & $99.0472 \%$ \\
275 & のலง & $(=\mathrm{pau})$ & $0.0155 \%$ & $99.0627 \%$ \\
\hline
\end{tabular}

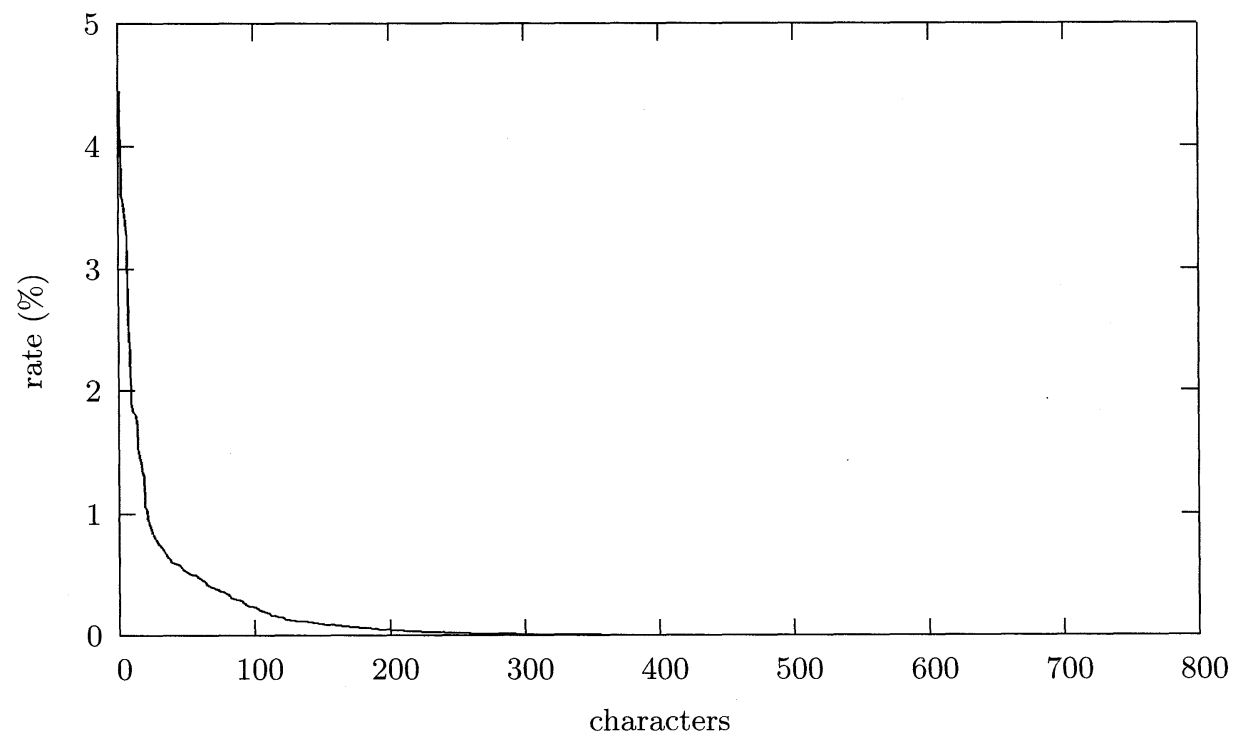

Fig. 2 Occurrence rates of characters

Unfortunately, such a standard conversion rule does not exist for Sinhala. Therefore userfriendliness of a Sinhala input method with typical English keyboards should be primarily dependent on the applicability of the underlying conversion rule, which in our proposal, is based on principled phonetic transcription.

For our evaluation, the most popular Sinhala input methods, which are the kaputadotcom (direct input), Natural SinGlish, and Sri Shell as shown in Figure 1, have been taken into account. First of all it is necessary to know the occurrence rates of each Sinhala character, because an efficient input system must be more efficient with frequent characters. For this purpose, the Divaina online Sinhala newspaper ${ }^{3}$ from January 2005 to May 2006 (about 50MB of kaputadotcom

\footnotetext{
3 http://www.divaina.com/
} 


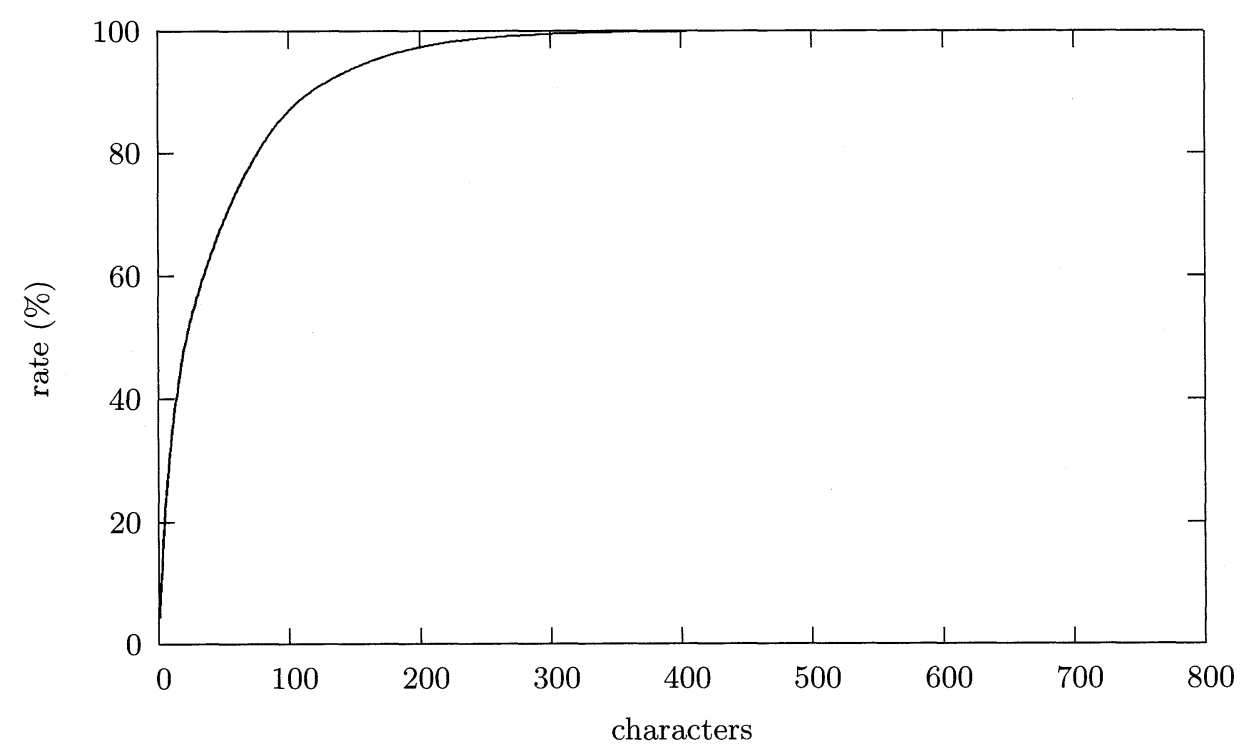

Fig. 3 Accumulated frequency

font text) was used as a corpus to calculate the occurrence rate of each Sinhala character.

In our evaluation 275 Sinhala characters were used, and this covers more than $99 \%$ of the characters occurred in the corpus, and all the characters have more than a $0.0155 \%$ occurrence rate.

\subsection{User-friendliness}

In order to produce an experiment more natural for the test subjects, we used a word list that includes all 275 characters mentioned above, instead of using the characters separately. We tried to minimize the number of words in order to reduce the test subjects' load. However, the word list ended up with 106 words. The difference between the input sequences and test subjects' romanization proposals is taken as a measure of how difficult it is to remember the input sequence for each Sinhala character.

\section{Romanizing Experiment}

Test subjects were asked to romanize the above Sinhala word list. This experiment was carried out on a group of 30 subjects between 14 to 60 years old, which included 14 males and 16 females. The romanized word lists we got from the subjects were split into characters. Then the difference between the input key sequence of each input method and the proposed romanized sequence of 
Table 9 Average edit distances

\begin{tabular}{|l|r|}
\hline Input Method & Average edit distance \\
\hline kaputadotcom & 1.42 \\
Natural SinGlish & 0.35 \\
Sri Shell & 0.44 \\
\hline
\end{tabular}

each test subject was measured by the edit distance between the two strings.

\section{Edit Distance}

The Levenshtein distance or edit distance between two strings is given by the minimum number of operations needed to transform one string into the other, where an operation is an insertion, deletion, or substitution of a single character (Wagner and Fischer 1974).

$$
\begin{gathered}
\text { avg_edit_dist }(\text { chr })=\frac{1}{\# \_S u b s} \sum_{\text {subject }=1}^{\#-S u b s} \text { edit_dist }(\text { input_sequence }(\text { chr }), \text { proposal }(\text { subject }, \text { chr })) \\
\text { average }=\sum_{c h r=1}^{\#-C h a r s} f r e q(\text { chr }) \cdot \text { avg_edit_dist }(\text { chr })
\end{gathered}
$$

\section{Results}

As a measurement of user-friendliness, we have calculated the average edit distance between an input key sequence and the proposed romanization of each character. The average edit distances of each input method are calculated using Equations 4 and 5 and are shown in Table 9. The results show that there is a big difference between the subjects' proposals and the input sequence proposed by kaputadotcom. In Natural SinGlish and Sri Shell the differences are very small. However, Natural SinGlish is slightly more user-friendly than Sri Shell. This happened because the test subjects always tried to produce a romanized Sinhala word that resembles an English word. So they tried to avoid key combinations such as "aa", "uu" and "ii", which are very rare in English. However, Sri Shell uses these as long vowels because repeated keys are more efficient in typing. The other reason is, Natural SinGlish has adopted a lot of English-like input sequences, where Sri Shell emphasizes more phonetic transcription.

\subsection{Efficiency}

The most general way to calculate efficiency is to experimentally compute the maximum typing speeds for each input method. However, for several reasons this method is not applicable to Sinhala. 
- Sinhala has hundreds of characters with very low occurrence rates. Thus, it is not fair to take a short paragraph for calculating the efficiency.

- Most of the Sinhala computer users are used to typing Sinhala based on only one input method. Therefore, the experimental results will be biased.

- In order to calculate the efficiency, we need to calculate peak typing speed, but in Sri Lanka, people who have good experience with the above three input methods are very rare.

Hence, instead of the actual typing speed we used the typing cost, which represents the normalized typing speed.

We define the weight of average time taken to input one single key stroke as 1 . The weight of shifted keys and the repeated keys may differ from 1. As a measurement of efficiency we have calculated the average typing cost of the input key sequences for each input method. We have defined the typing cost of the input sequence as Equation 6. Experiments 1 and 2 are carried out in order to calculate the weights of shifted keys and repeated keys.

$$
\begin{aligned}
\text { typing_cost } & =w_{\text {shift }} \times \text { shifts }+w_{\text {repeat }} \times \text { repeats }+1 \times \text { normal_keys } \\
w_{\text {shift }} & =\frac{t_{x Y}+t_{X y}}{t_{x y}}-2 \\
w_{\text {repeat }} & =\frac{t_{x x}}{t_{x y}}
\end{aligned}
$$

where,

$t_{x y}=$ average time lapse between two alpha key strokes

$t_{x x}=$ average time lapse to repeat an alpha key stroke

$t_{x Y}=$ average time lapse between an alpha key and a shifted alpha key

$t_{X y}=$ average time lapse between a shifted alpha key and an alpha key

\section{Experiment 1}

Test subjects are asked to type a set of character pairs. Some pairs consist of two different characters and in the others the two characters are the same. Then $t_{x y}$ and $t_{x x}$ are calculated by averaging them. This experiment was carried out on a group of 12 subjects ( 3 female and 9 male, Age 18-46 years).

\section{Experiment 2}

The test subjects are asked to type a set of common English words, but some characters of the word are capitalized. Then $t_{x y}, t_{x Y}$ and $t_{X y}$ are calculated by averaging them. This experiment 
was carried out on a group of 11 subjects (7 female and 4 male, Age 20-31 years).

\section{Least Square Method}

The trend of the above experiment data is estimated using the least square method. The trend is approximated into a line (Equation 9). $b$ and $m$ are calculated, which minimize the $\sum\left(y-a c t u a l_{-} d a t a\right)^{2}$.

$$
\begin{aligned}
y & =m x+b \\
m & =\frac{\sum(x-\bar{x})(y-\bar{y})}{\sum(x-\bar{x})} \\
b & =\bar{y}-m \bar{x} \\
r & =\frac{n \sum x y-\left(\sum x\right)\left(\sum y\right)}{\sqrt{n \sum x^{2}-\left(\sum x\right)^{2}} \sqrt{n \sum y^{2}-\left(\sum y\right)^{2}}}
\end{aligned}
$$

The experiment results are shown in Figures 4 and 5 . The $\mathrm{X}$-axis shows $t_{x y}$, the average time lapse between two alpha key strokes, while the Y-axis shows the weights of repeated keys and the shift key.

The equations of the approximation lines and the coefficient correlations are shown in Equations 13 and 14.

Weight of repeated key

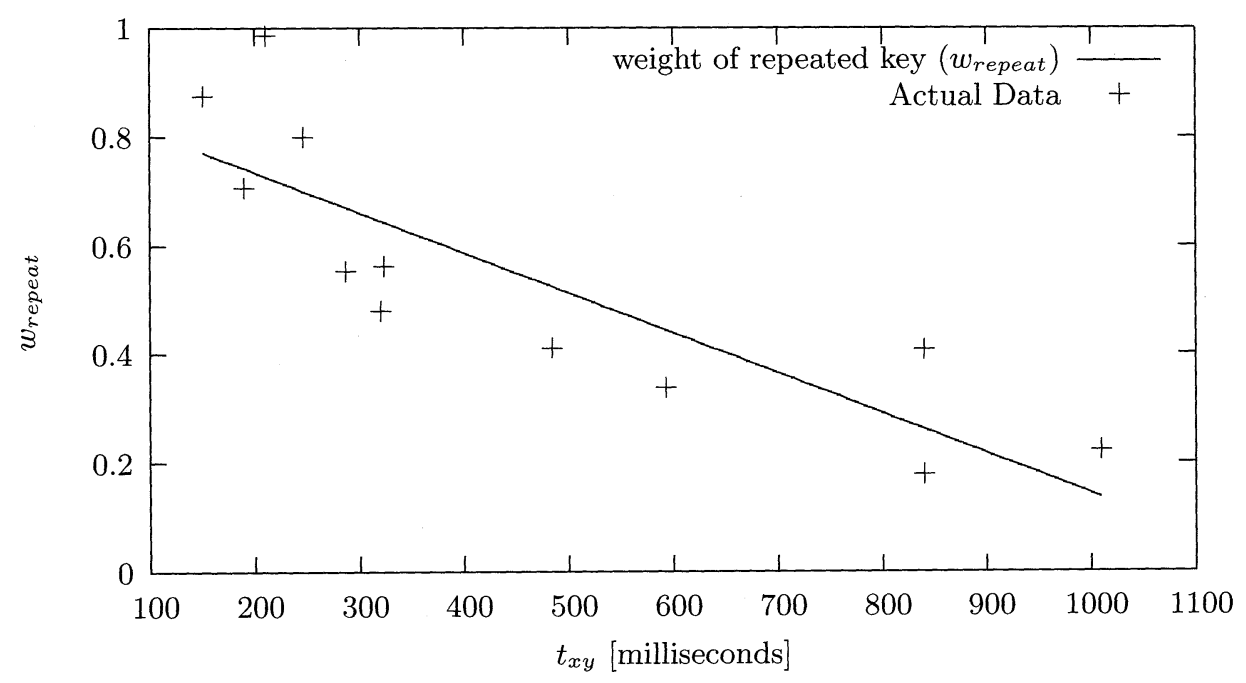

Fig. 4 Weight of repeated keys 


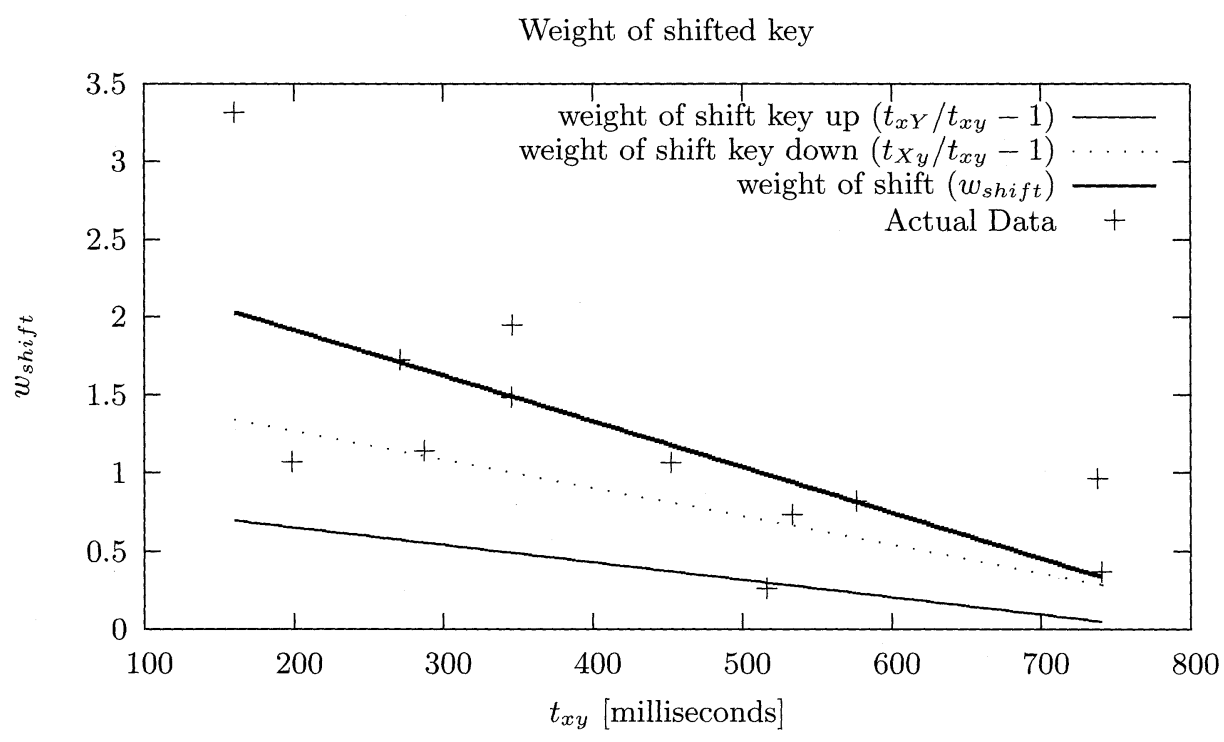

Fig. 5 Weight of shift key

\section{Results}

The average typing cost for each input method is calculated using Equation 15, and the results are shown in Table 10. These results show that Sri Shell has the lowest typing cost among the three input methods except for $t_{x y}=600 \mathrm{~ms}$. Even though our results show that kaputadotcom has the lowest typing cost for $t_{x y}=600 \mathrm{~ms}$, kaputadotcom is not recommendable even to the slow typists, because kaputadotcom is not user-friendly. This means that Sri Shell is the most efficient input method. Sri Shell has the best results because Sri Shell uses lowercase alpha characters and "/" only, where the other methods use a lot of uppercase characters and a lot of symbols (for example “), @,\#,\$"). There are a lot of drawbacks in using uppercase characters and symbols. It increases the users' load and error rates. As our target is average computer users in Sri Lanka, who are quite familiar with English typing, they do not feel a conceptual difference with case differences. The other problem is that a mixture of symbols, uppercases and lowercases results in

Table 10 Average typing cost

\begin{tabular}{|c|c|c|c|}
\hline$t_{x y}$ & kaputadotcom & Natural SinGlish & Sri Shell \\
\hline 200 & 2.60 & 2.26 & 2.18 \\
400 & 2.30 & 2.22 & 2.16 \\
600 & 1.99 & 2.16 & 2.13 \\
\hline
\end{tabular}


an unreadable input sequence (for example kuruNA) gala or $k O r \# N \$ g l$ ). One may argue that this is just an input method and there is no need for readability. However, if a sequence is readable it will be easier to memorize, and for an application like $\mathrm{AT}_{\mathrm{E}} \mathrm{X}$ where one has to type without any output feedback, it is an advantage if what is typed can be read.

$$
\begin{aligned}
w_{\text {repeat }} & =0.87-0.73 t_{x y} \quad(|r|=85 \%) \\
w_{\text {shift }} & =2.50-2.92 t_{x y} \quad(|r|=69 \%) \\
\text { average } & =\sum_{\text {chr }=1}^{\#-C h a r s} \text { freq }(\text { chr }) \cdot \text { weight }(\text { chr })
\end{aligned}
$$

\section{Conclusions and Future Work}

We have proposed a Sinhala input method Sri Shell ${ }^{4}$, which is based on Sinhala phonetic transcription. We evaluated the user-friendliness and efficiency of the method by comparing it with other Sinhala character input methods such as kaputadotcom and Natural SinGlish.

All the Sinhala input methods proposed up to now have a one-to-one (or many-to-one) relationship between the input sequence and output characters. This is the simplest way to design an input method, and these kinds of input systems require very few resources (less memory or disk space). For this reason, these input methods can be implemented even on mobile terminals, etc. However, the romanization experiment results revealed that there were certain character contexts that require many-to-many correspondences. Figure 6 shows some examples.

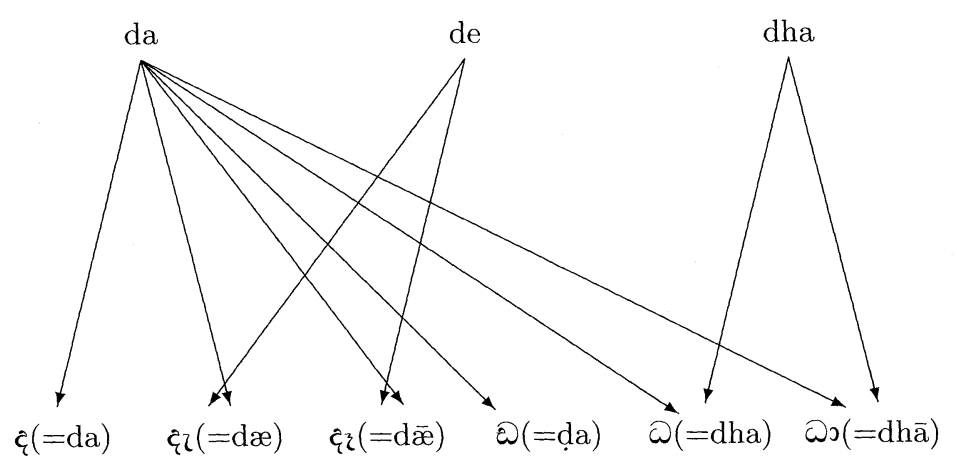

Fig. 6 Some many-to-many relationships in test subjects' proposals

\footnotetext{
${ }^{4}$ http://www.sandeva.com/sri_shell/
} 
In order to improve the user-friendliness of the proposed method, our future work is to incorporate these correspondences into the method, which will require the development of a contextsensitive character conversion algorithm.

\section{Acknowledgment}

The authors would like to thank Mr. Goonetilleke M.D.N.G. for the collection of experiment data from the 30 test subjects.

\section{Reference}

Davis, M. (2006). Text Boundaries, Unicode Standard Annex \#29. http://unicode.org/reports/tr29/.

Dominic Hughes, O. B. and Warren, J. (2002). "Empirical Bi-action Tables: a Tool for the Evaluation and Optimization of Text Input Systems, Application I: Stylus Keyboards." ACM Transactions on Computer-Human Interaction (TOCHI), 17, pp. 131-169.

Gordon, R. G. (2005). Ethnologue: Languages of the World, Fifteenth edition. SIL International http://www. ethnologue.com/family_index.asp.

Indrasēna, D. (2001). sinhala akshara mālāva. Sridevi Printers (pvt) Ltd.

Masui, T. (1998). "An efficient text input method for pen-based computers." Proceedings of the SIGCHI conference on Human factors in computing systems, pp. 328-335.

Mikami, Y. (2002). A History of Character Codes in Asia (in Japanese). Kyoritsu Publishing Co.

Sasanka, A. D. R. (2004). Natural Singlish. http://www.geocities.com/naturalsinglish/.

State, U. S. D. O. (2007). Background Note: Sri Lanka. http://www.state.gov/r/pa/ei/bgn/5249.htm.

Unicode (2007). Glossary of Unicode Terms. http://unicode.org/glossary/.

Wagner, R. A. and Fischer, M. J. (1974). "The String-to-String Correction Problem." Journal of the ACM, 21 (1), pp. 168-173.

Sandeva Goonetilleke: Sandeva Goonetilleke received his B.E, and M.E. degrees from Osaka university in 2004 and 2006 respectively. He is currently a Ph.D candidate, and pursuing a research on Sinhala computing as his doc- 
toral theme. His research interests include natural langugae processing, human interfaces, and character input systems especialy for indic scripts.

Yoshihiko Hayashi: Yoshihiko Hayashi received his B.E, M.E, and Dr.Eng. degrees from Waseda university in 1981, 1983, and 1996 respectively. He has been a professor of graduate school of language and culture, Osaka university since 2004. Before moved to Osaka university, he had been a researcher at NTT laboratories, working on natural language processing technologies associated with Japanese-to-English machine translation, Japanese text revision, crosslanguage information retrieval, and speech-based multi-media indexing. He is now additionally affiliated with NICT language grid project, where he is working on a domain ontology for describing language resources and NLP tools in the context of language infrastructure on the web. His research interests include natural language processing, intelligent information access, and lexical ontologies.

Yuichi Itoh: Yuichi Itoh received his B.E, M.E, and Ph.D. degrees from Osaka university in 1998, 2000, and 2006 respectively. He has been an assistant professor of graduate school of information science and technology, Osaka university since 2002 . His research interests include realizing natural and intuitive human-computer interactions.

Fumio Kishino: Fumio Kishino received the B. E., M. E. and D. E. degrees from Nagoya Institute of Technology, Nagoya, Japan, in 1969, 1971 and 1995, respectively. In 1971, he joined NTT laboratories, where he was involved in work on research and development of image processing and visual communication systems. From 1989 to 1996 he was a head of Artificial Intelligence Department, ATR Communication Systems Research Laboratories, where he was engaged in research on virtual space teleconferencing. In July 1996, he became a Professor of Graduate School of Engineering, Osaka University. Since April 2002, he is a Professor of Graduate School of Information Science and Technology, Osaka University. His research interests include human interface in virtual environment and multimedia content processing.

(Received March 22, 2007)

(Revised May 3, 2007)

(Rerevised May 30, 2007)

(Accepted June 20, 2007) 